\title{
Analysis of the Development of Rural E-commerce under the View of Big Data
}

\author{
Wang Jiantao \\ E-commerec College of Business Xi'an International University, Shaanxi China, 710061
}

Keywords: agriculture; big data; e-commerce; development

Abstract: The information age is a challenge and an opportunity for agriculture. In particular, big data technology and Internet data technology have provided new opportunities for agricultural development. It is mainly reflected in the farmers' use of big data technology to analyze the price trend of agricultural production materials, scientifically and rationally arrange the production of agricultural products, avoiding the listing of the agricultural products, thereby achieving greater economic benefits; in the sales chain, using the Internet technology to open an e-commerce platform, in the government With the support of logistics companies, universities, scientific research institutions to cooperate, do a good job in the packaging, publicity, logistics and transportation, preservation, and capital transfer of agricultural products, so that the agricultural product sales area is wider and larger.

\section{Introduction}

The era of informationization is the era of big data. Every industry and field has gathered big data. It provides various data and authoritative references for the issue of "agriculture, rural areas and farmers". Good use and management of big data can promote the development of rural e-commerce and realize the "13th Five-Year Plan" proposal of the Fifth Plenary Session. The meeting proposed to implement the national big data strategy and promote the development and sharing of data resources. With the rapid development of the market economy, the topic and research on big data at home and abroad are in full swing. The data is considered to be a strategic resource to seize market opportunities and a treasure for future development. According to the computing power revolution brought by cloud computing, for the processing and analysis of big data resources, the people corresponding to these data are found, and then these groups are personalized and analyzed, and the personalized service is gradually become may.

\section{Development of the era of agricultural big data}

Agricultural information services should take the initiative to keep up with the arrival of the big data era to adapt to future development trends. With the opportunities brought by big data technology, we will focus on agricultural and rural informatization services and strive to achieve the development of agriculture and rural e-commerce. The important way of agricultural data reflects the gradual formation of data values. From the perspective of regional location, it is necessary to 
take domestic data as the core and international agricultural data as reference. This includes not only important national data, but also regional-level and municipal-level specific regional research. From a professional perspective, effective steps should be implemented. First, a professional data resource should be established in agricultural production, and secondly, data resources should be planned step by step. Such as the market demand for pigs, cattle, chickens, ducks and other dynamic data, annual agricultural research activities have a large number of data integration, the mining and utilization of these data is extremely important for the development of modern agriculture.

\section{Agricultural big data helps agricultural development}

The development of agriculture plays an important role in human beings. On the one hand, agriculture provides an indispensable material element for human survival. On the other hand, agriculture has laid the foundation for the development of industry and other industries. Natural factors are one of the important factors affecting agricultural production. Developing regional characteristic economy, optimizing agricultural structure, improving agricultural management mode, and mobilizing production enthusiasm are the basics of developing agriculture. Therefore, we must pay attention to climate, soil, geographical location and others in agricultural production. The influence of natural factors. Data collection, data mining, and data statistics reflect the characteristics of agricultural production and changes in external environment, and facilitate the prediction or adjustment of agricultural production, capital injection, and technical improvement. Traditional agricultural production relies mainly on experience guidance, and the harvest and expected errors are relatively large. Using agricultural data analysis, we can avoid data loss and analyze all the data, which can greatly improve the prediction accuracy and make timely response in agricultural production. It can provide information for the selection of new varieties, the status of use of fertilizers, and the growth of harvest[1].

\section{Problems with agricultural big data}

Although big data has been used in some areas of our daily lives, there is still a misunderstanding of agricultural data. First of all, big data is suspected of excessive hype. Many people also think that big data is just mass storage, a platform for more information, and lack of core value. Second, some people think that big data can solve all problems, and that traditional data analysis and processing methods will be replaced by big data. These two extremes of understanding are not advisable. The existence and development of big data is the inevitable result of information progress. We must face it correctly and use it to better serve the development of society. It is worth noting that the current big data concepts, technologies, and methods are not yet mature. The big data prediction results are not accurate, but rely on algorithms and processes to provide possibilities, and more people need guidance[2].

\section{China's rural development e-commerce trend}

According to figures released by the National Bureau of Statistics, as of the end of 2013, China's rural population was 630 million, accounting for $46.3 \%$ of the total population. In recent years, with the advancement of urbanization, the proportion of rural population in the overall population has continued to decline, but the proportion of rural netizens in the overall netizens has continued to rise. Rural areas have become an important driving force for the growth of netizens in China. . According to the figures released by China Internet Network Information Center, as of December 2013, the proportion of rural population in China's Internet users was 28.6\%, with a scale of 177 million, an increase of 21.01 million compared with 2012. However, the Internet penetration rate of 
rural residents in China is only $27.5 \%$, which is not far from the $62 \%$ of urban residents. This also indicates that there is a lot of room for future growth[3]. The development trend of rural e-commerce is as follows.

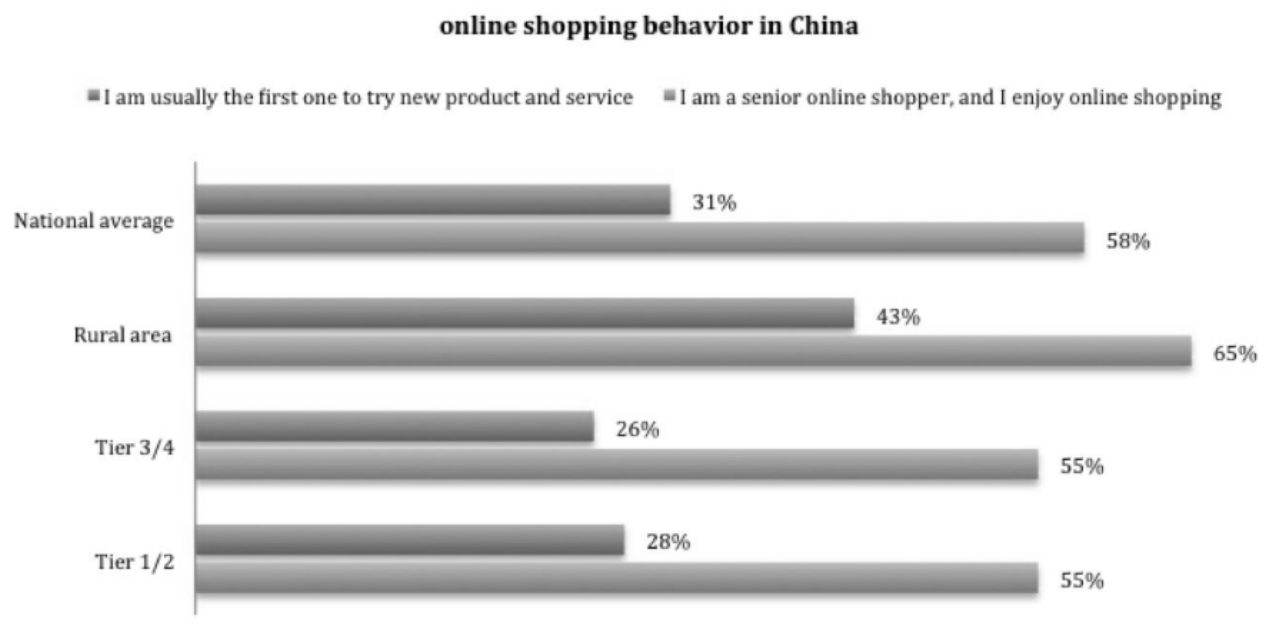

Fig.1 Development trend of rural e-commerce

\section{Common problems in the development of rural e-commerce in China}

\subsection{Rural e-commerce has not caused enough attention of the county (district) government}

Rural e-commerce did not attract enough attention, resulting in the lack of professional knowledge and technical personnel in the grassroots government of townships, poor hardware facilities, low number of computers, low utilization rate, serious shortage of agricultural information collection and analysis personnel, and lagging development of rural e-commerce.

\subsection{City-administered counties lack e-commerce public service centers}

In the process of rural e-commerce development, the five main components of the government, platform, network operators, suppliers and service providers are intertwined and need a strong platform guarantee. E-commerce public service center is such a platform, and many cities, counties (districts) in Guangxi lack such a platform, can not play the role of public service centers; can not tap local specialty products, provide platform docking and marketing promotion; can not cultivate, support, Serve the county (district) e-commerce development[4].

\subsection{Rural e-commerce lacks complete and smooth logistics channels}

Logistics distribution in many areas has basically achieved full coverage, but the distribution of rural markets is limited. In addition to China Post, the main express delivery companies such as SF Express and Yuantong can only be located in towns and towns, and the layout of townships and towns is not comprehensive. Some towns and towns have no outlets. Although some distribution areas can go to towns and villages, only self-delivery services are available. Due to the lack of complete and smooth logistics channels and the involvement of e-commerce, even if farmers have the demand for e-commerce, they cannot be satisfied, let alone the online sales of agricultural products. 


\subsection{Rural low-quality e-commerce practitioners}

Rural e-commerce personnel are generally not subject to vocational training, lack of understanding of commodity collection and dissemination of information, social feedback, and often disadvantaged in a highly competitive society. Farmers will use fewer computers, and the logistics and distribution methods used by farmers are lagging behind. The backwardness of freezing and preserving methods also hinders the promotion and application of agricultural products[5].

\section{Discussion on the development of rural informatization}

\subsection{To establish an agricultural big data information management system}

The design and development of agricultural big data information management system can build agricultural e-commerce information platform in the form of bidding through government service outsourcing. The ranking of Taobao e-commerce in rural areas of China is as follows.

\begin{tabular}{|c|c|c|c|c|c|} 
Ranking & Province & $\begin{array}{c}\text { Number of } \\
\text { Taobao Villages }\end{array}$ & Ranking & Province & $\begin{array}{c}\text { Number of } \\
\text { Taobao Villages }\end{array}$ \\
\hline 1 & Zhejiang & 62 & 6 & Shandong & 13 \\
\hline 2 & Guangdong & 54 & 7 & Sichuan & 2 \\
\hline 3 & Fujian & 28 & 8 & Henan & 1 \\
\hline 5 & Hebei & 25 & 9 & Tianjin & 1 \\
\hline
\end{tabular}

Fig.2 Ranking of Taobao e-commerce in rural areas of China

The agricultural big data information management system platform should have the following information: 1. Three rural policy information and poverty alleviation information, including various poverty alleviation and benefit policies, documents and poverty alleviation measures in the old revolutionary areas, ethnic areas, border areas and poverty alleviation areas. Let the poor people understand in time and use effective policies flexibly to improve the self-awareness and initiative of poor households. Detailed information on poverty-stricken areas, including family population, left-behind children, empty-nest elderly, health status, family property, and causes of poverty, must ensure the transparency and transparency of poverty information. Help the responsible person information, including the means of assistance, responsibility, progress in poverty alleviation, etc. or guide the assessment information. Rural industrial development information, including industrial development planning and project promotion information, such as local characteristic industries in various cities and counties, agrochemical product development information, circulation information, and farmhouse tourism development projects. 2. Information on rural property rights transactions, namely rural land transfer, land management rights, agricultural production facilities and other information. By accelerating the transfer of land and implementing modest scale operations, a number of characteristic industrial bases and large-scale breeding towns with quality and scale will be formed, and a village and a product will be formed to guide farmers' "cooperative (company) + base + farmer" mode. Rural financial poverty alleviation information should take the initiative to play the role of regional and rural financial service systems and carry out financial poverty alleviation work. For example, in the deepening of rural financial reform, Guangxi has used the financial poverty alleviation data platform to promote poverty alleviation work, and has made effective exploration and practice, and has achieved gratifying results, which is worth learning and 
promoting. 3. Information on rural infrastructure construction, including information on housing projects, ecological immigration, and road construction. Rural public service information, including social power counterpart assistance, tracking assistance, agricultural insurance, rural credit, agricultural loan guarantee and other service information. Rural education poverty alleviation information, including poverty alleviation family student funding, skills training, employment training information, and enhance the employment function of poor households.

\subsection{The government must do a good job in field research and develop a development plan}

E-commerce must be developed in rural areas. The government must make development plans and financing policies, use the relevant national development policies to build appropriate e-commerce facilities in rural areas, and communicate with enterprises so that enterprises can participate. In addition, an important part of the research process that cannot be ignored is to listen to the opinions and opinions of farmers and formulate development plans.

\section{Summary}

Since rural information is relatively independent, in the process of development, it is necessary to improve the publicity of rural electronic information, so that some people take the initiative to use the e-commerce platform. These people learn to use the electronic platform to drive other people to learn together and develop together. They are improving rural e-commerce with the help of government and businesses. With the continuous development of the social economy, e-commerce is embarking on the road of development little by little in the countryside. In the process of development, we must find practical solutions to eliminate e-commerce in rural areas.

\section{References}

[1] Luo Zhendong, He Heming, Li Caige.A New Bottom-Up Process: The Rural Urbanization Driven by E-Commerce in China[J].China City Planning Review,2017,26(04):25-33.

[2] Xu Chan, Lü Bin, Wen Tianzuo,Qian Fang.New Patterns of County In-Situ Urbanization and Rural Development: Perspective of E-Commerce [J].China City Planning Review,2017,26(04):34-41.

[3] Yan Wang. A Study on the Targeted Poverty Alleviation Path of Rural E-commerce in Shaanxi Province[A]. Research Institute of Management Science and Industrial Engineering.Proceedings of 2017 th International Conference on Business, Economics and Management(BUSEM 2017)[C].Research Institute of Management Science and Industrial Engineering:,2017:5.

[4] Lixin TANG.Problems in Development of Rural E-commerce and Logistics and Recommendations[J].Asian Agricultural Research,2016,8(12):41-42+47.

[5] Changyu LIU,Jiale LI,Jing LIU.Rural E-commerce and New Model of Rural Development in China:A Comparative Study of "Taobao Village" in Jiangsu Province[J].Asian Agricultural Research,2015,7(11):35-37+46. 